\title{
New Aureothin Derivative, Alloaureothin, from Streptomyces sp. MM23
}

\author{
Jun-ya Ueda, Junko Hashimoto, Aya Nagai, Takuji Nakashima, Hisayuki Komaki, \\ Kozue Anzai, Shigeaki Harayama, Takayuki Doi, Takashi Takahashi, Kazuo Nagasawa, \\ Tohru Natsume, Motoki Takagi, Kazuo Shin-ya
}

Received: February 28, 2007 / Accepted: April 25, 2007

(C) Japan Antibiotics Research Association

\begin{abstract}
A new polypropionate alloaureothin (1) possessing a nitro group, together with a known polypropionate aureothin (2), was isolated from mycelium of Streptomyces sp. MM23. The structure was determined on the basis of spectroscopic data. 1 exhibited growth inhibitory effect against human fibrosarcoma HT1080 cells with an $\mathrm{IC}_{50}$ value of $30 \mu \mathrm{M}$.
\end{abstract}

Keywords polypropionate, alloaureothin, Streptomyces sp., cytotoxic

Polypropionates with a nitro group, a class of polyketides, were isolated from several actinomycetes and displayed interesting biological activities. Aureothin (2) isolated from the mycelium of Streptomyces thioluteus [1] was reported to exhibit antifungal, antitumor, and anti-Helicobacter pylori activities [2]. Spectinabilin (3) isolated from the culture broth of Streptomyces spectinabilis [3] showed inhibitory activity against reverse-transcriptase in Rausche leukemia virus and antimalarial activity [4]. In the course

K. Shin-ya (Corresponding author), T. Natsume: Biological Information Research Center (BIRC), National Institute of Advanced Industrial Science and Technology (AIST), 2-42 Aomi, Koto-ku, Tokyo 135-0064, Japan,

E-mail: kshinya@jbirc.aist.go.jp

M. Takagi (Corresponding author), J. Ueda, J. Hashimoto, A. Nagai: Japan Biological Information Research Center (JBIRC), Japan Biological Informatics Consortium (JBIC), 2-42 Aomi, Koto-ku, Tokyo 135-0064, Japan,

E-mail: mtakagi@jbirc.aist.go.jp of our screening program for biological active compounds of microbial origin, we isolated a new aureothin derivative, designated as alloaureothin (1), from mycelium of Streptomyces sp. MM23 (Fig. 1).

The Streptomyces sp. MM23 isolated from soil sample collected in Hiroshima Prefecture, Japan, was cultured at $27^{\circ} \mathrm{C}$ for 5 days in $500-\mathrm{ml}$ Erlenmeyer flasks containing a medium consisting of $2.5 \%$ starch, $1.5 \%$ soy bean meal, $0.2 \%$ dry yeast, $0.4 \% \mathrm{CaCO}_{3}$ ( $\mathrm{pH} 6.2$ before sterilization). The whole culture broth (2 liters) was centrifuged, and the mycelial cake was extracted with acetone $(400 \mathrm{ml})$. The extract was evaporated in vacuo, and the residual aqueous concentrate was extracted with ethyl acetate. The organic layer $(157 \mathrm{mg})$ was separated by silica gel flash column (Purif-Pack SI-60, Moritex) with a $n$-hexane - ethyl acetate linear gradient system $(0 \sim 100 \%$ EtOAc). The $50 \sim 100 \%$ EtOAc eluate was further purified by reversed-phase HPLC ( $70 \%$ aqueous $\mathrm{MeOH}$ ) with Senshu Pak PEGASIL ODS column $(20 \mathrm{~mm}$ i.d. $\times 250 \mathrm{~mm})$ to give a new compound 1 (Rt 38.8 minutes, $2.5 \mathrm{mg}$ ) and 2 (Rt 41.8 minutes, $8.3 \mathrm{mg}$ ) [1]. In both isolation procedures, peak detection was carried out by UV absorption at $254 \mathrm{~nm}$. A structurally

T. Nakashima, H. Komaki, K. Anzai, S. Harayama: NITE Biological Resource Center (NBRC), National Institute of Technology and Evaluation (NITE), 2-5-8 Kazusakamatari, Kisarazu, Chiba 292-0818, Japan

T. Doi, T. Takahashi: Graduate School of Science and Engineering, Tokyo Institute of Technology, 2-12-1 Ookayama, Meguro-ku, Tokyo 152-8552, Japan

K. Nagasawa: Department of Biotechnology and Life Science, Tokyo University of Agriculture and Technology, 2-24-16 Nakacho, Koganei, Tokyo 184-8588, Japan 
related compound, 3 was obtained from another strain in the course of our chemical screening program. The structure elucidation of $\mathbf{1}$ was carried out mainly by NMR spectral analyses and a comparison with these compounds as follows.
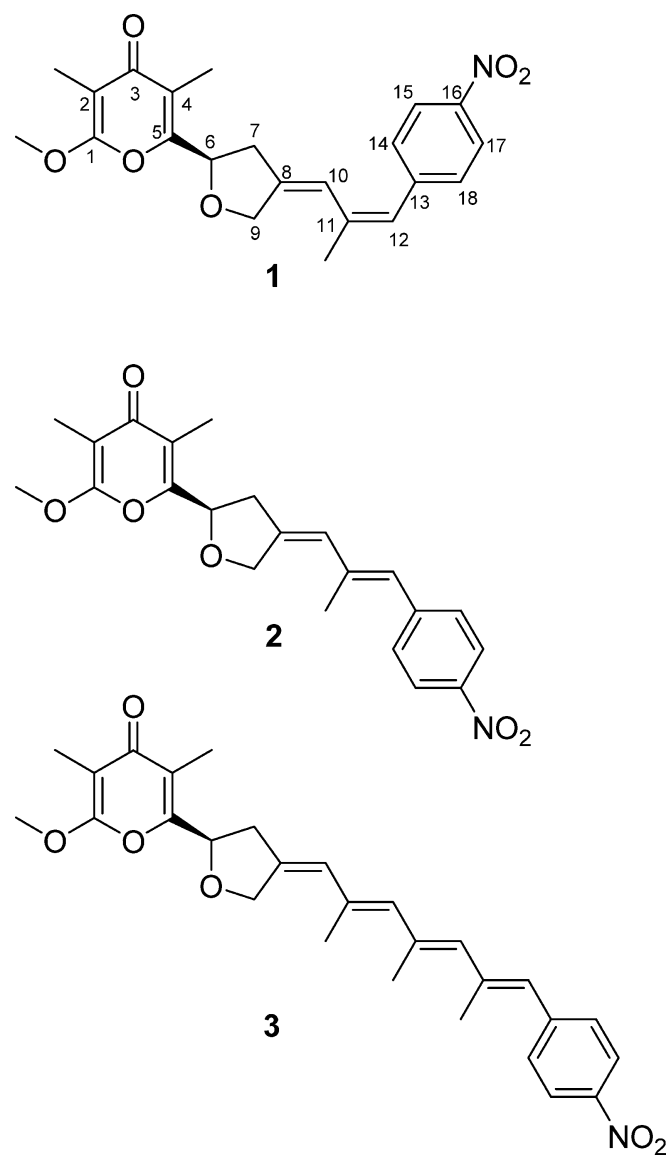

Fig. 1 Structures of alloaureothin (1), aureothin (2) and spectinabilin (3).
1 was obtained as a yellowish amorphous solid and showed similar UV spectrum $\left(\lambda_{\max }, 255,334 \mathrm{~nm}\right)$ to that of 2 on HPLC (detector: Hitachi L-2455 diode array detector). Its physico-chemical properties are summarized in Table 1. The molecular formula was established as $\mathrm{C}_{22} \mathrm{H}_{23} \mathrm{NO}_{6}$ from HR-ESI-MS data $(\mathrm{m} / \mathrm{z}$ 398.1628). The IR spectra revealed the characteristic absorption of a nitro groups $\left(v_{\max } 1592,1342 \mathrm{~cm}^{-1}\right)$, together with carbonyl group ( $v_{\max }$ $1666 \mathrm{~cm}^{-1}$ ). The ${ }^{1} \mathrm{H}-$ and ${ }^{13} \mathrm{C}-\mathrm{NMR}$ spectra of $\mathbf{1}$ (Table 2) showed the signals of a 1,4-disubstituted phenyl group [C$13\left(\delta_{\mathrm{C}} 144.6\right), \mathrm{C}-14,18\left(\delta_{\mathrm{H}} 7.39 ; \delta_{\mathrm{C}} 129.7\right), \mathrm{C}-15,17\left(\delta_{\mathrm{H}}\right.$ $\left.\left.8.17 ; \delta_{\mathrm{C}} 123.7\right), \mathrm{C}-16\left(\delta_{\mathrm{C}} 146.3\right)\right]$, a conjugated ketone group C-3 $\left(\delta_{\mathrm{C}} 180.7\right)$, eight olefins [C-1 $\left(\delta_{\mathrm{C}} 162.3\right), \mathrm{C}-2$ $\left(\delta_{\mathrm{C}} 100.4\right), \mathrm{C}-4\left(\delta_{\mathrm{C}} 120.4\right), \mathrm{C}-5\left(\delta_{\mathrm{C}} 154.6\right), \mathrm{C}-8\left(\delta_{\mathrm{C}} 142.1\right)$, $\mathrm{C}-10\left(\delta_{\mathrm{H}} 6.35 ; \delta_{\mathrm{C}} 119.9\right), \mathrm{C}-11\left(\delta_{\mathrm{C}} 138.0\right), \mathrm{C}-12\left(\delta_{\mathrm{H}} 6.39 ;\right.$ $\left.\left.\delta_{\mathrm{C}} 127.6\right)\right]$, an oxymethine group C-6 $\left(\delta_{\mathrm{H}} 5.10 ; \delta_{\mathrm{C}} 73.9\right)$, an oxygenated methylene C-9 $\left(\delta_{\mathrm{H}} 4.65,4.49 ; \delta_{\mathrm{C}} 70.5\right)$, a methoxyl group $1-O-\mathrm{Me}\left(\delta_{\mathrm{H}} 3.92 ; \delta_{\mathrm{C}} 55.5\right)$, a methylene $\mathrm{C}$ $7\left(\delta_{\mathrm{H}} 2.96,2.89 ; \delta_{\mathrm{C}} 38.1\right)$, and three vinyl methyl groups [2-Me $\left(\delta_{\mathrm{H}} 1.85 ; \delta_{\mathrm{C}} 7.1\right), 4-\mathrm{Me}\left(\delta_{\mathrm{H}} 2.01 ; \delta_{\mathrm{C}} 9.7\right)$, and $11-$ $\left.\operatorname{Me}\left(\delta_{\mathrm{H}} 2.07 ; \delta_{\mathrm{C}} 24.3\right)\right]$. The HMBC together with ${ }^{1} \mathrm{H}-{ }^{1} \mathrm{H}$ COSY spectra established a tetrasubstituted $\gamma$-pyrone, a 2,4-disubstituted furan, a 1,3-butadiene, and a 1,4disubstituted benzene units as shown in Fig. 2A. The connectivity between these substructures was established by the long-range ${ }^{1} \mathrm{H}-{ }^{13} \mathrm{C}$ couplings from $12-\mathrm{H}$ to $\mathrm{C}-13$ and $\mathrm{C}-14,18$, from $10-\mathrm{H}$ to $\mathrm{C}-7$ and $\mathrm{C}-9$, and from $7-\mathrm{H}$ and $6-\mathrm{H}$ to $\mathrm{C}-5$. The methoxyl proton $1-O-\mathrm{Me}$ was long-range coupled to $\mathrm{C}-1$. Long-range couplings between the methyl proton 2-Me and $\mathrm{C}-1, \mathrm{C}-2$, and $\mathrm{C}-3$, together with the longrange couplings between $4-\mathrm{Me}$ and $\mathrm{C}-3, \mathrm{C}-4$, and $\mathrm{C}-5$ revealed the substituted pattern in the $\gamma$-pyrone moiety. The remaining nitro functional group was determined to be substituted at $\mathrm{C}-16$ by IR absorption and comparison of the chemical shifts with 2 .

Table 1 Physico-chemical properties of alloaureothin (1) and aureothin (2)

\begin{tabular}{lll}
\hline & \multicolumn{1}{c}{$\mathbf{1}$} & \multicolumn{1}{c}{$\mathbf{2}^{\mathrm{a}}$} \\
\hline Appearance & Yellowish amorphous solid & Yellow prism \\
MP & $50.5 \sim 55.0^{\circ} \mathrm{C}$ & $158^{\circ} \mathrm{C}$ \\
Optical rotation & {$[\alpha]_{D}^{25}-29.7^{\circ}\left(c 0.12, \mathrm{CHCl}_{3}\right)$} & {$[\alpha]_{D}^{18}+51^{\circ}\left(\mathrm{CHCl}_{3}\right)$} \\
Molecular formula & $\mathrm{C}_{22} \mathrm{H}_{23} \mathrm{NO}_{6}$ & $\mathrm{C}_{22} \mathrm{H}_{23} \mathrm{NO}_{6}$ \\
HR-ESI-MS $(\mathrm{m} / \mathrm{z})$ & & \\
$\quad$ found & $398.1628(\mathrm{M}+\mathrm{H})^{+}$ & \\
calcd & 398.1604 & $257(4.39), 346(4.27)$ \\
UV $\lambda_{\max }^{\mathrm{MeOH}} \mathrm{nm}(\log \varepsilon)$ & $255(4.3), 334(4.0)$ & 1505,1321 \\
IR $v_{\max }(\mathrm{KBr}) \mathrm{cm}^{-1}$ & $1666,1592,1516,1342$ & \\
\hline
\end{tabular}

\footnotetext{
a Reported data by Hirata et al. [1].
} 
Table $2{ }^{1} \mathrm{H}(500 \mathrm{MHz})$ and ${ }^{13} \mathrm{C}(125 \mathrm{MHz}) \mathrm{NMR}$ data of $\mathbf{1}$ and $\mathbf{2}$ in $\mathrm{CDCl}_{3}$

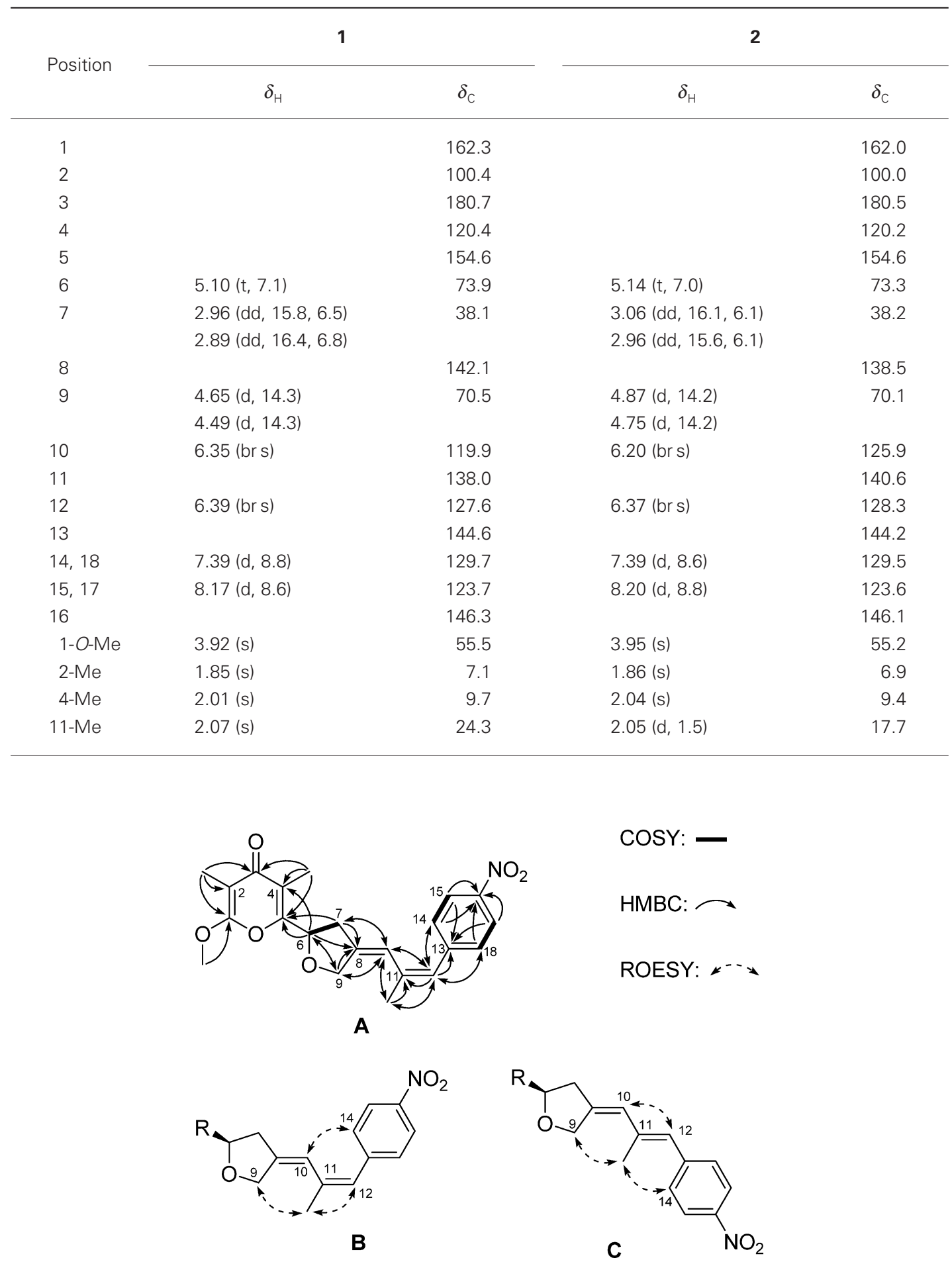

Fig. 2 Key correlations in ${ }^{1} \mathrm{H}^{1} \mathrm{H}$ COSY and HMBC experiments of $\mathbf{1}(\mathrm{A})$, and ROESY experiments of $\mathbf{1}$ (B) and $\mathbf{2}$ (C), respectively. 
The stereochemistry of olefins at C-8 and C-11 proved to be $E$ and $Z$, respectively, based on the ROE correlations between $9-\mathrm{H}$ and 11-Me, between 11-Me and 12-H. ROE between $10-\mathrm{H}$ and $14,18-\mathrm{H}$ and low-field ${ }^{13} \mathrm{C}$ chemical shift at $11-\mathrm{Me}\left(\delta_{\mathrm{C}} 24.3\right)$ compared with high-field ${ }^{13} \mathrm{C}$ chemical shift in $\mathbf{2}$ also supported the stereochemistry as shown in Fig. 2B (also shown ROE correlations of $\mathbf{2}$ in Fig. 2C). The same Cotton effects among $\mathbf{1 ,} \mathbf{2}$ and $\mathbf{3}$ in CD spectra (1, $[\theta]_{240} 4510,[\theta]_{281}-2118 ; \mathbf{2},[\theta]_{223} 5152,[\theta]_{281}-3034 ; \mathbf{3}$, $\left.[\theta]_{215} 4845,[\theta]_{249}-2172,[\theta]_{281}-3626\right)$ revealed that the absolute configuration at C-6 to be $R$. In addition to the CD spectra, $\mathbf{1}$ was gradually transformed to $\mathbf{2}$ in methanol solution, indicating that they possess the same configuration. Thus, the structure of $\mathbf{1}$ was established to be 11-cis aureothin as shown in Fig. 1. As the derivative of $\mathbf{2}$, an isomeric compound RP-18051 was reported in French Patent 1,516.739. Although this compound showed the different optical rotation value from 2 , the melting point was much higher than that of $\mathbf{1}$. Taking into consideration these results, this compound could be $6 S$ aureothin.

The three isolated compounds were examined for their growth inhibitory activity toward the highly metastatic human HT-1080 fibrosarcoma cell line. Compounds $\mathbf{1}$ and $\mathbf{2}$ inhibited the cell growth in a concentration-dependent manner with the $\mathrm{IC}_{50}$ values of 30 and $60 \mu \mathrm{M}$, respectively. To the contrary, 3 which consist of a highly resembled structure did not show any cytotoxic activity in HT1080 cells at concentration of $100 \mu \mathrm{M}$. Studies on detailed biological activities of $\mathbf{1}, \mathbf{2}$, and $\mathbf{3}$ are now underway.
Acknowledgement This work was supported by the grant from the New Energy and Industrial Technology Development Organization (NEDO) of Japan.

\section{References}

1. (a) Maeda K. Chemical studies on antibiotic substances, IV. A crystalline toxic substance of Streptomyces thioluteus producing aureothricin. J Antibiot, Ser. A 6: 137-138 (1953) (b) Hirata Y, Nakata H, Yamada K, Okuhara K, Naito T. The structure of aureothin, a nitro compound obtained from Streptomyces thioluteus. Tetrahedron 1961: 252-274 (1961)

2. (a) Schwartz JL, Tishler M, Arison BH, Shafer HM, Omura S. Identification of mycolutein and pulvomycin as aureothin and labilomycin respectively. J Antibiot 29: 236-241 (1976)

(b) Taniguchi M, Watanabe M, Nagai K, Suzumura K, Suzuki K, Tanaka A. $\gamma$-Pyrone compounds with selective and potent anti-Helicobacter pylori activity. J Antibiot 53: 844-847 (2000)

3. Kakinuma K, Hanson CA, Rinehart Jr KL. Spectinabilin, a new nitro-containing metabolite isolated from Streptomyces spectabilis. Tetrahedron 32: 217-222 (1976)

4. Isaka M, Jaturapat A, Kramyu J, Tanticharoen M, Thebtaranonth Y. Potent in vitro antimalarial activity of metacycloprodigiosin isolated from Streptomyces spectabilis BCC 4785. Antimicrob Agents Chemother 46: 1112-1113 (2002) 